\title{
Ironie as sleutel tot die verstaan van Psalm 141
}

P J Botha

\section{ABSTRACT}

\section{Irony as key to the interpretation of Psalm 14}

The Gattung of a psalm is generally still regarded as the key to its interpretation. Since Psalm 14 shows relatedness to a number of different genres, inter alia to wisdom literature and prophecy, there is little or no consensus on how it should be interpreted. It is argued in this paper that the textual strategy of a poem such as Psalm 14 should be regarded as the key to its interpretation rather than a genre classification. Through a poetic analysis of Psalm 14 it is shown that irony plays such a key role in the psalm. Cognizance of this feature of the psalm focusses attention on its coherence and unity and opens up a new avenue of understanding.

\section{DIE PROBLEMATIEK VAN PSALM 14}

Ten spyte van die feit dat hierdie psalm twee maal in die Psalmbundel opgeneem is ${ }^{2}$, is daar verskil in mening oor die Gattung ${ }^{3}$, struktuur ${ }^{4}$, datering en interpretasie ${ }^{5}$ daarvan. Vele ondersoekers het gewys op die wysheids- en profetiese invloed 6 op 'n psalm wat andersyds algemeen as 'n klaaglied beskryf word. Aangesien die meeste kommentare steeds die Gattung van 'n psalm as die sleutel vir die interpretasie neem, bestaan daar uiteenlopende menings oor wat die strekking van die psalm is ${ }^{7}$. Die interpretasie van die psalm wat hier aangebied word, is gegrond op die veronderstelling dat die psalm van 'n bepaalde teksstrategie gebruik maak om 'n boodskap oor te dra. Hierdie teksstrategie kan die resultaat wees van die intensie van 'n skeppende outeur, of dit kon ontstaan het as gevolg van wysigings wat deur een of meer verwerkers van 'n oorspronklike teks aangebring is. As hipotese word gestel dat ironie die teksstrategie van Psalm 14 vorm $^{8}$, en dat erkenning van hierdie feit tot meer bevredigende konklusies oor die betekenis van die psalm lei as 'n vertrekpunt wat op die veronderstelde Gattung van die psalm gegrond is.

In die lig van die bestaan van 'n doeblet van hierdie psalm, sou dit raadsaam wees om 'n literêr-kritiese ondersoek na die verwantskap van die teks van die twee psalms te loods. Hierdie diakroniese ondersoek word met opset eerste gedoen ten einde by die poëtiese analise van die psalm, wat 'n 
sinkroniese ondersoek van die finale teksgestalte verteenwoordig, met groter sekerheid oor die teksstrategie te kan praat. 'n Voorlopige ondersoek het naamlik getoon dat die verskille in die twee weergawes meebring dat ironie in Psalm 53 'n veel kleiner rol speel. As laaste fase sal dan gepoog word om die betekenis van die psalm (in sy huidige vorm) te peil.

\section{DIE VERWANTSKAP TUSSEN DIE TEKS VAN PSALM 14 EN VAN PSALM 53}

Psalm 14 verskil op die volgende plekke van Psalm 53:

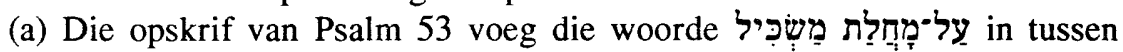

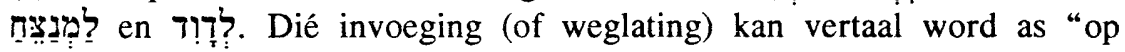
Máhalat, 'n onderwysing". Daar is geen eenstemmigheid oor die betekenis van מָּחָלָ nie. Dit kom verder slegs in Psalm 88:1 voor. Die Translator's Handbook ${ }^{9}$ reken dit is 'n verwysing na of 'n musiekinstrument of 'n wysie. Dit is nie moontlik om met sekerheid te sê dat die twee opskrifte wel 'n variant verteenwoordig nie. Daar moet rekening gehou word met die moontlikheid dat die psalm in twee verskillende bundels reeds vroeg van twee verskillende opskrifte voorsien is ${ }^{10}$.

(b) Vers 1c verskil in twee opsigte van die weergawe in Psalm 53: Psalm 53 voeg 'n waw-kopulatief tussen die eerste twee woorde in; en לy word gelees in die plek van die עִ עִ עִ van valm 14. Laasgenoemde term is 'n neutrale term 11 , wat as objek van תעב (veragtelik handel) 'n moeilike konstruksie daarstel en mens laat dink dat beide wysigings in Psalm 53 se weergawe aangebring is om die teks te vergemaklik. Dit is ook die konklusie van Kraus ${ }^{12}$.

(c) Die יהוה van vers 2a, 4e, 6b en 7c word, soos reeds vermeld, met אלהים vervang in Psalm 53. Die vraag oor watter weergawe ouer of "meer oorspronklik" is, moet hier weer aan die orde gestel word. By die deurlees van die twee psalms val dit op dat die weergawe in Psalm 53 minder spontaan en meer kunsmatig voorkom. In Psalm 53:3 byvoorbeeld (vers 2 in Psalm 14), lyk die gebruik van אלהים lomp, al vorm dit 'n soort inclusio. Omdat dieselfde subjek as objek opgeneem word, sou 'n objekmerker plus suffiks gemakliker gelees het aan die einde van die sin. Wanneer אלהים met afgewissel word, is beide die grammatika én die betekenis minder problematies. Dieselfde geld ook van die laaste vers: in samehang met die gebruik van die eiename ישראל', sou die eienaam יהוה baie beter pas. Op grond van hierdie oorwegings lyk dit aanneemlik om te aanvaar dat Psalm 14 die ouer weergawe is. 


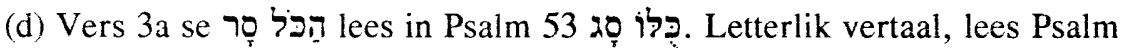
14:3a dus: "Die geheel het afgewyk" en Psalm 53:4a: "Sy geheel het teruggegly". Die wysiging van die werkwoord kan hier toegeskryf word

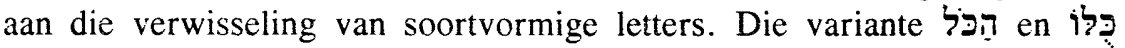
moet egter opsetlike tekswysiging wees. Die vorm met suffiks, soos in Psalm 53 gebruik, vorm 'n beter parallel met en is moontlik 'n harmonisering.

(e) Vers 4b se כָכָל ontbreek in Psalm 53. Die rede daarvoor is nie duidelik nie. Moontlik is dit 'n geval van haplografie.

(f) Psalm 14:5 en Psalm 53:6 verskil grootliks van mekaar:

Psalm 14:5 en 6:

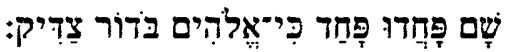

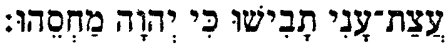

Psalm 53:6:

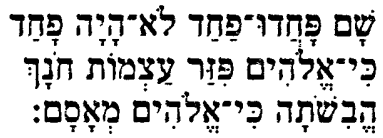

Met die eerste oogopslag wil dit voorkom of Psalm 14 twee weglatings ondergaan het as gevolg van haplografie: לפּוֹר tot by הברשתזה. In vertaling klink Psalm 53 se weergawe egter lomp: "Daar het hulle van vrees gebewe waar geen vrees is nie, want God het die bene verstrooi van dié een van jou wat kamp opslaan (of: van dié een wat teen jou kamp opslaan ${ }^{13}$ ), jy het (hulle) beskaam, want God het hulle verwerp". Psalm 14:5 en 6 word só vertaal: "Daar het hulle van vrees gebewe, want God is onder die geslag van die regverdige. Die raad van die ellendige wil julle beskaam, maar Jahwe is sy skuilplek!14". 'n Vergelyking van die Hebreeuse konsonantteks toon hoe 'n onduidelike manuskrip waarskynlik aanleiding gegee het tot die twee weergawes:

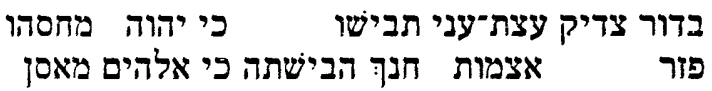

Beide weergawes skep probleme15. Al die woorde wat in die twee reëls voorkom, is egter goed bekend in die Psalms. 'n Besluit op grond van woordkeuse is dus nie maklik nie. Vers $5 \mathrm{~b}$ en $6 \mathrm{~b}$ van Psalm 14 vorm 'n parallel, maar dieselfde kan gesê word van Psalm 53:6b en 6c. Die saak moet voorlopig onbeslis gelaat word, maar daar sal later gepoog word om aan te toon dat Psalm 14:5 en 6 meer kongruent is met die res van die psalm, en dus as geslaagde rekonstruksie of as meer outentieke weergawe beskryf kan word ${ }^{16}$. 


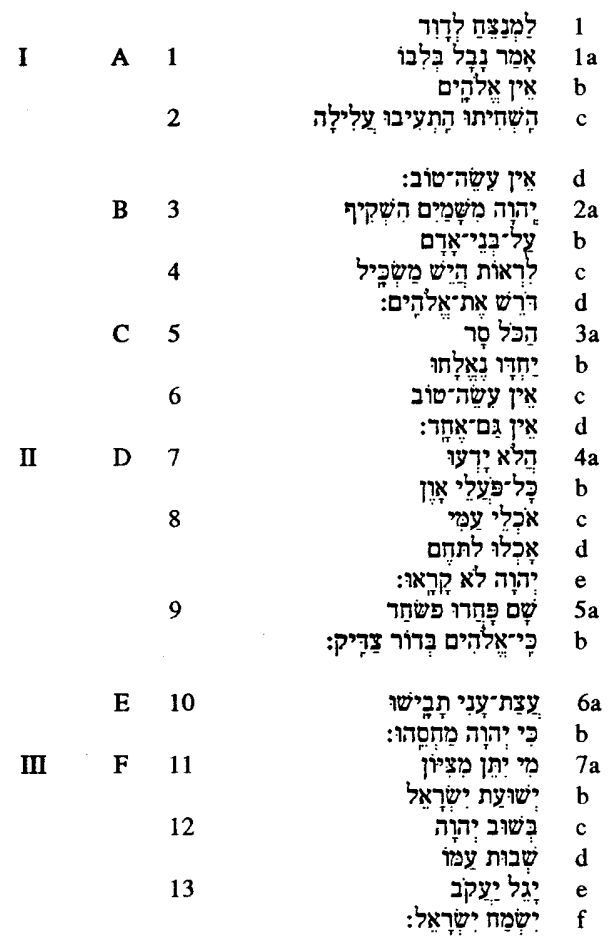

Vir die musiekleier. Van Dawid.

Die dwaas sê in sy hart

"Daar is geen God nie".

Hulle tree verderflik op, hulle doen veragtelike dade,

daar is nie een wat goed doen nie.

Jahwe kyk uit die hemel af

op die mense,

om te sien of daar 'n wyse is,

iemand wat God opsoek.

Hulle het almal afgewyk,

almal saam is korrup;

daar is nie een wat goed doen nie,

daar is selfs nie een nie.

Weet hulle nie,

al die kwaaddoeners

wat my volk opeet

asof hulle brood eet

maar Jahwe nie aanroep nie,

dat hulle daar in groot vrees sal verkeer nie?

Waarlik, God is onder die geslag van die regverdige.

(Julle) raad (teen) die arme sal verydel word, want Jahwe is sy skild.

Mag daar uit Sion

verlossing vir Israel kom.

Wanneer Jahwe

die lot van sy volk sal herstel, sal Jakob van vreugde roep, sal Israel hom verheug.

Psalm 14 as gedig kan in 13 versreëls verdeel word (genommer met 1 tot 13 links van die Hebreeuse teks). Hiervan is die oorgrote meerderheid distiges met twee of drie klemtoonheffings. Slegs versreël 8 (vers $4 \mathrm{c}-\mathrm{e}$ ) is 'n tristige met metrum $2+2+3$. Die versreëls kan in ses strofes saamgegroepeer word (aangedui met A-F), wat op hulle beurt in drie stansas gegroepeer kan word (aangedui met I-III). Stansa I beskryf die wedersydse besinning oor en beoordeling van die mensdom teenoor God en God teenoor die mens. Die dwaas se verbale (versreël 1) en praktiese (versreël 2) ontkenning van God se bestaan gaan nie ongemerk verby nie. Jahwe kyk af om te sien of daar 'n uitsondering is (strofe B, versreël 3 en 4). Sy bevinding word in strofe $C$ gedokumenteer: Daar is niemand wat met Hom rekening hou nie. In Stansa II lewer God kommentaar oor die toedrag van sake. Die goddelose, wat deur drie eienskappe getipeer word 
(versreël 7 en 8 ), gaan hulle rieme styfloop. Hulle gaan verskrik wees as hulle ontdek dat God wel bestaan, en dat Hy presies daar is waar hulle goddeloosheid tot uiting kom - in die uitbuiting van sy volgelinge (versreël 9). Strofe E (versreël 10) bereik 'n hoogtepunt deurdat die goddelose direk aangespreek word, en die bestaan van God onder sy volk weer as feit gestel word. Vers 7 verteenwoordig 'n wending. Dit is 'n wens (gebed) om herstel wat baie kunstig geformuleer is. Die gebruik van assonansie (e-uklanke), alliterasie (jod, sin, sjin en beth) en rym ( $m i, s j u, j a$ en jis) bind dit saam tot 'n hegte eenheid. Die slotwoorde van elke hemistige in vers 7 vorm 'n patroon: Sion, Israel, Jahwe, sy volk, Jakob, Israel. Jahwe en sy volk word omring deur name en word sodoende in hierdie gebed ten nouste verenig. Vers 7c bevat woordspel waardeur 'n binding bewerk word tussen "by die omkeer" en "die lot van sy volk".

Klank speel in die res van die gedig (Stansa I en II) ook 'n belangrike rol: Die $h i$ en $i$-klanke in versreël 2; die prominente repetisie van (טֵל (vers 1 b, d en 3 c,d), טוֹ (vers 1d en 3c) en sekere stamme in vers $4 c$ en d en פחד in vers 5a). Laasgenoemde verteenwoordig 'n geval

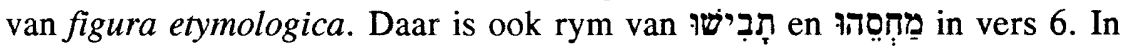
vers $2 \mathrm{a}$ is daar inversie, enjambement in vers $2 \mathrm{c}$-d en versreël 7 en 8 , 'n chiasme in vers 4 (perfektum, partisipium, partisipium, perfektum) en 'n uitgebreide parallelisme in vers 4 (die vyf laaste elemente van elke hemistige vorm die patroon abcba).

\section{DIE FUNKSIE VAN IRONIE IN PSALM 14}

Sekerlik die belangrikste kenmerk van die gedig is egter die polariteit wat gevorm word tussen die nominale ontkennings en nominale bevestigings. Hierby inbegrepe is die wysheidspolariteit van dwaas teenoor wys en die polariteit tussen God en godloënaar. Indien die gedig uit hierdie perspektief opgesom word, lewer dit die volgende gedagtegang:

Dwaas: daar is geen God nie (nominale ontkenning) (vers 1)

Verteller ${ }^{17}$ : daar is niemand wat goed doen nie (nominale ontkenning) (vers 1)

daar is niemand wat goed doen nie (nominale ontkenning) (vers 3)

daar is selfs nie een nie (nominale ontkenning) (vers 3)

God is onder die geslag van die regverdige (nominale bevestiging) (vers 5)

Jahwe is die arme se skild (nominale bevestiging) (vers 6) 
Die gebruik van nominale ontkenning en bevestiging konstitueer in hierdie geval ironie: God bestaan wel - Hy bestaan in die geslag van die regverdige, Hy bestaan as skuilplek van die arme. Omdat die goddelose se ateïstiese belydenis in 'n ateïstiese praktyk oorgaan (verdrukking van die volgelinge van God), wag 'n dubbele ontnugtering op hulle: hulle sal vind dat God wel bestaan, en dat Hy die Beskermer is van sy volk. Die psalm begin met die vraag na God se bestaan, beskryf dan Jahwe se waarnemings en ingrype, en identifiseer God en Jahwe dan met mekaar deur parallelle nominale bevestigings in vers 5 en 6 . Sy beoordeling van hulle optrede en insig is veel belangriker as hulle besinning oor sy bestaan al dan nie. Hulle bevinding dat $\mathrm{Hy}$ nie bestaan nie, staan in kontras met sy bevinding dat hulle (eties) nie bestaansreg het nie. Weiser ${ }^{18}$ reken dat die שם van vers $5 a$ verband hou met die tradisie waarvolgens God in die kultus as regter teenwoordig is. Dit lyk egter meer logies om dit op te neem as 'n merker wat prolepties in verband staan met hulle ontdekking van die teenwoordigheid van God onder die regverdiges, soos net in die volgende hemistige gesê word. Dus: "Daar sal hulle in groot vrees verkeer (wanneer hulle ontdek) God is waarlik onder die geslag van die regverdige".

\section{DIE BETEKENIS VAN PSALM 14 IN SY HUIDIGE VORM}

Soos reeds vroeër vermeld, het vele ondersoekers gewys op die "profetiese styl" 19 van Psalm 14. Dit kom byvoorbeeld na vore in die "profetiese" klag oor korrupsie (vers 1-4), die "profetiese" waarskuwing in vers 6 en die "profetiese" gebed in vers 7 . Indien die ondersoeker egter nie primêr op soek is na elemente van verskillende Gattungen nie, bied hierdie eienskappe hulleself aan as kenmerke van 'n narratiewe teks ${ }^{20}$. Ten einde die rol van die verteller duidelik te omskryf en karakterisering in die gedig bloot te lê, word die psalm onder die volgende (narratologiese) opskrifte bekyk:

\subsection{Die verteller in Psalm 14}

Die verteller, as narratologiese skepping, is in 'n onverbloemde, deelnemende gestalte aanwesig en kan as 'n "alwetende" verteller getipeer word. Hy haal aan wat "die dwaas" in sy gedagte sê en lewer kommentaar op die dwase se optrede (vers 1). Hy beskryf hoe God die menslike optrede beskou en deel die leser mee wat God se konklusie is, naamlik dat daar geen regverdige is nie (vers 2 en 3 ). In vers 4 tree hy sterk na vore met 
kritiese kommentaar op die dwase se optrede teenoor sy (die verteller se) volk $^{21}$. Hy voeg 'n bedekte waarskuwing daaraan toe. Hy deel die leser mee dat God self by die geslag van die regverdige is (vers 5) en gaan dan oor tot 'n openlike waarskuwing aan die goddelose dat hulle raad verydel sal word. Vers 7 is ' $n$ wensbede van die verteller dat Jahwe Israel se lot sal verander en 'n stelling dat daar vreugde sal wees wanneer dié wens vervul word. Die sekerheid waarmee die verteller in vers 1-6 uitsprake maak, word dus in vers 7 aansienlik getemper.

Daar is wel tematiese ooreenkomste tussen Psalm 14 en die profeteliteratuur en die verteller neem in vers 4-6 selfs die styl van die profeteboeke oor. Maar die masjal van vers 1 herinner eerder aan 'n wysheidsleraar, terwyl die beskrywing van vers 2 kennelik on-profeties van aard is en eerder met die verteller se beskrywing in die proloog van Job vergelyk kan word 22 .

\subsection{Die antagoniste}

$\mathrm{Na}$ hierdie groep word in vers 1 a generies as "die dwaas" verwys, mense wat die bestaan van God ontken (vers 1ab). Dieselfde subjek se wese en optrede word in vers $1 \mathrm{~cd}$ beskryf as mense wat verderflik optree en veragtelike dade doen, en wat nie die goeie doen nie. God vind onder hulle nie een wat wys is of wat God opsoek nie (vers $2 \mathrm{~cd})^{23}$. Hulle het almal afgewyk, word gesê. Hulle is almal korrup, daar is nie een onder hulle wat goed doen nie (vers 3 ). Vers $4 b$ beskryf hulle as mense wat boosheid bedryf. Hulle is mense wat God se volk opeet (vers 4c) en Jahwe nie aanroep nie (vers $4 \mathrm{e}$ ). Uit vers $6 \mathrm{a}$ is ook bekend dat hulle planne beraam teen die "arme/ellendige".

Hierdie beskrywings laat die leser dink dat dit Israeliete is waarvan hier gepraat word - mense wat God behoort aan te roep (vers 4e), maar dit nie doen nie ${ }^{24}$. Hulle is mense met mag (vers 4c) wat die onskuldige minderbevoorregte uitbuit (vers 6a). Aan die ander kant is die tipering in vers $2 b$ baie algemeen gestel: "mense/mensdom". Hierdie "mensheid" staan egter in kontras met die "my volk" in vers $5 b$ en die "geslag van die regverdige" in vers $5 \mathrm{~b}$. Dit beteken dat die moontlikheid tog oopgelaat moet word dat die antagoniste opgeneem moet word as behorende tot ander volke, naas en teenoor Israel. Wanneer vers 7 ook by die bespreking betrek word, word dit duidelik dat die protagoniste en antagoniste wel as vyandige nasies bedoel word: "Sion", "Israel", "sy volk", "Jakob" en weer 'n keer "Israel" is beskrywings wat Israel as 'n homogene geheel afgrens teenoor ander volke. 
Die protagoniste het reeds by die vorige paragraaf ter sprake gekom. Opsommend kan gesê word dat hulle as "my volk", "die geslag van die regverdige" en "die arme" getipeer word in die eerste en tweede hoofdeel van die gedig. Volgens Anderson 25 is die terme "regverdige" en "arme" sinoniem. Hulle vorm 'n bepaalde sosiale stratum. Vers 7 beskryf hulle egter eerder as 'n politieke entiteit. Omdat die woord $\mathrm{y}$ in beide vers 4c en vers $7 \mathrm{~d}$ gebruik word, is dit duidelik dat die psalm in sy huidige teksgestalte oor die polariteit tussen Israeliet en nie-Israeliet handel. Die Israeliete word dus (soms bloot by implikasie) getipeer as "wys", mense wat "God opsoek", mense wat "goed doen" en wat "Jahwe aanroep".

\subsection{Die helper}

Die helper, Jahwe, is in hierdie gedig die een wie se bestaan deur die antagoniste ontken word. Om daardie rede teister die antagoniste die protagoniste met veragtelike optrede. Die helper bemerk en ondersoek hulle optrede egter. Sy ondersoek vind plaas "uit die hemel". Hy is dus in 'n posisie van mag en daarom het die dreigement dat die antagoniste deur vrees geteister sal word, meer effek. Jahwe is egter nie slegs in die hemel nie, Hy is ook by/onder die geslag van die regverdige. Hy is ook in Sion aanwesig, want die gebed in vers 7 lui dat verlossing vir sy volk uit daardie oord sal kom ${ }^{26}$. Eindelik word gesê dat God wel die lot van sy volk sal verander, vir hulle verlossing sal bring (slegs die tyd van hierdie gebeure is onseker, nie die gebeurtenis self nie - vergelyk vers 7c). Die psalm eindig met twee parallelle imperfekta ${ }^{27}$, sprekend van die sekerheid oor die afloop van die drama.

Die dominante teksstrategie van die psalm is dus om 'n dubbele polariteit te bewerkstellig. Enersyds word die goddelose (al word die antagoniste nooit by dié naam genoem nie) gepolariseer met die

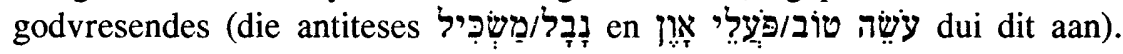
Andersyds word die goddelose ook gepolariseer met God self. Hulle denke en optrede getuig daarvan dat hulle die bestaan van God ontken; maar hulle denke en optrede veroorsaak dat God hulle die bestaansreg ontneem. Ook die aktiwiteit van die goddelose vorm 'n polariteit met die bestaan van God in die gedig. Daar is ' $n$ opstapeling van aksiewoorde wanneer die goddelose beskryf word (hulle "sê", "tree verderflik op", "doen veragtelike dade", "het afgewyk", "is korrup", "eet die volk op"; maar "doen nie 
goed nie", "soek God" nie, "weet" nie, "roep Jahwe" nie aan nie). Daarteenoor is God se optrede en bestaan versluierd (Hy "kyk af", Hy "is"). Deur gebruik te maak van nominale ontkennings en bevestigings, in samehang met kontrasterende uitbeelding, word ironie bewerkstellig. Ironie dien in hierdie gedig om die bestaan van God en die sekerheid van sy ingrype in die verontregting van sy volgelinge te bevestig.

Dit is om hierdie rede dat Psalm 14:5 en 6, wat dus twee nominale bevestigings van God se bestaan bevat, as meer kongruent met die res van die gedig, en dus as meer geslaagd beskou moet word dan die weergawe in Psalm 53. Ironie is baie sterker op die voorgrond en speel 'n groter rol in die weergawe van Psalm 14.

\section{$6 \quad$ Konklusie}

Soos met baie psalms die geval is, is die Gattung en Sitz im Leben van Psalm 14 nie duidelik omskrewe nie. Dit is onseker watter plek dit in Israel se liturgie beklee het. Uit die ondersoek is wel duidelik dat die psalm in sy huidige vorm uit die eksiliese of na-eksiliese tyd stam ${ }^{28}$. Daar is egter in 'n paar opsigte interne spanning tussen vers $1-6$ en vers 7 merkbaar ${ }^{29}$. Dit is moontlik dat vers 1-6 deel gevorm het van 'n ouer lied wat oor die interne polariteit tussen maghebber en onderdaan binne God se volk gehandel het. Wanneer vers 7 as deel van die gedig gelees word, transponeer dit die polariteit om Israeliete en ander nasies in te sluit, en veronderstel dit die onderwerping van "Israel" aan vreemde oorheersers.

Hoewel vers 7 dus elemente van ' $n$ klaagliedstyl bevat, is die oorheersende impak dié van 'n polariteit tussen God se volk (of volgelinge) en die goddelose, en tussen God en die goddelose. God se bestaan en sy bestaan tussen sy volgelinge, skep ironiese spanning met die opvatting dat Hy nie bestaan nie en die dwase lewenshouding wat hierdie opvatting vergesel. Vers 5 vorm 'n klimaks omdat dit 'n snypunt verteenwoordig tussen die goddelose se opvatting oor God en die realiteit van God se bestaan. Die verskrikking wat die goddelose gaan oorval se intensiteit word verhoog deurdat hulle teoretiese en praktiese ateïsme gesamentlik ontnugter gaan word omdat God juis tussen die regverdiges, die objek van hulle uitbuiting, aanwesig is. In vers 7 word God se bestaan selfs 'n adres gegee, wanneer gesê word dat die verlossing uit Sion sal kom. So vind die sewende vers ook aansluiting by die ironie van die eerste twee stansas.

Die boodskap dat God wel 'n verskil maak, dat dit die moeite werd is om in sy bestaan en sy ingrype te bly glo, was nie alleen vir die na-eksiliese Israel relevant nie (vergelyk Mal 3:14-18), dit is universeel en 
a-histories. Hierdie boodskap kan egter alleen raakgesien word as die gedig as afgeronde geheel gelees word en nie op grond van 'n Gattungsondersoek gefragmenteer word nie. Ook die pogings om dit met 'n bepaalde kultiese situasie te verbind en teen daardie agtergrond te verstaan, doen die psalm 'n onreg aan. Om dit op grond van die styl van vers 7 te tipeer as 'n "klaaglied" ${ }^{0}$, of om dit te beskou as 'n aanval van die profete op die priesters $^{31}$ is om die ironie, en die strekking van die gedig, mis te kyk.

\section{NOTAS:}

Finansiële ondersteuning van die Sentrum vir Wetenskap-Ontwikkeling van die Raad vir Geesteswetenskaplike Navorsing tot 'n navorsingsprojek oor poëtiese konvensies in die Psalms aan die Universiteit van Pretoria word hiermee erken. Die menings wat uitgespreek word en die gevolgtrekkings waartoe gekom word, is nie noodwendig die opinie van die SWO of die RGN nie.

Die ander weergawe is die "Elohistiese" Psalm 53. Daar word nêrens in die ander weergawe na יהוה verwys nie. (Die Elohistiese psalm is die bundel van Psalms 42-83.)

A A Anderson, The Book of Psalms, Vol I, Psalms 1-72, Grand Rapids 1981, 130, sê dit is onduidelik wat die Gattung is, maar dat dit baie ooreenkomste met die Profetiese en Wysheidsliteratuur vertoon. Westermann tipeer dit as 'n soort klaaglied waarin die aandag sodanig op die Frevler toegespits is, dat die voorspoed en val van die vyand 'n polariteit vorm (C Westermann, Lob und Klage in den Psalmen, Göttingen 51977, 147). Zenger (F-L Hossfeld \& E Zenger, Die Psalmen I, 1-50, Würzburg 1993, 99) beskryf vers 1-5 as "prophetische Klageliturgie", 'n mengsel van wysheid en profetiese oorlewering. Gunkel het verskeie genres daarin teruggevind: in vers 1-3 'n "profetischen Scheltrede", in vers 4-6 'n "Drohrede" en in vers 7 'n kort gebed (H Gunkel, Die Psalmen, übersezt und erklärt, Göttingen 61986, 232). Kraus sien veral profetiese en wysheids-invloed in 'n aangepaste klaaglied (H-J Kraus, Psalms 1-59, A commentary, translated by H C Oswald 1988, 220-221). Deissler tipeer dit sonder meer as 'n psalm uit die “Gattung der Klagelieder”. Vergelyk sy bespreking in A Deissler, Die Psalmen, Düsseldorf 1964, 64. J P M Van der Ploeg, Psalmen, Deel I, Psalm I tot met 75, Roermond 1973, 93, noem dit 'n "klacht", maar reken dat dit ook bedoel kan wees as 'n "vrome overweging" of "publiek gebed na privé of publieke lezing van een historisch tekst sprekend van Israëls verleden”.

Van der Ploeg, $a w, 94$, deel dit in twee dele (vers 1-3 en vers 4-7). Anderson, $a w, 131$, verdeel dit in drie dele, te wete vers 1-3, 4-6 en 7. Dit is ook die indeling van A Weiser, The Psalms, a commentary, translated by H Hartwell, London 1975, 164 en R A Bennett, "Wisdom motifs in Psalm $14=53$ - nabal and 'esah", Bulletin of the American Schools of Oriental 
Research 220 (1975), 15. Zenger, $a w, 100$, groepeer die verse só: 1,2-3, $4,5,6$ en 7 .

Datering en interpretasie gaan gewoonlik hand aan hand. Die verskil van opinie het veral te doen met die indentifikasie van die aktante. Weiser, $a w$ 164 , dink dat die psalm gebruik is teen die leierskap in Israel wat hulle minderbevoorregte volksgenote verdruk. Van der Ploeg, $a w, 96$, plaas die psalm in die na-eksiliese tyd en is onseker of heidennasies teenoor Israel gestel word en of bloot individuele vyande van die vrome veroordeel word. Hy neig in die rigting van laasgenoemde opsie, maar sien die objek van die gebed in vers 7 tog ook as die versameling van die verstrooide Israel ( $a w$, 97).

Vir 'n volledige bespreking van die wysheidsmotiewe in Psalm 14 kan Bennett se studie geraadpleeg word: $\mathrm{R} \mathrm{A}$ Bennett, $a w, 15-21$. In sy kommentaar op Psalm 53 het Gunkel uitvoerige aantekeninge oor profetiese parallelle met die psalm gemaak. Vergelyk Gunkel, $a w, 232-235$ en verder ook Deissler, $a w, 64-65$, en J Jeremias, Kultprophetie und Gerichtsverkündigung in der späten Königszeit Israels, Neukirchen-Vluyn 1970, 114-117.

Van der Ploeg, $a w, 94$, merk op: "De opvattingen zouden niet zo uiteenlopen, wanneer genre en bedoeling duidelijker zouden zijn”.

Zenger, $a w, 103$, het wel ook die ironie tussen vers 1 en vers 6 raakgesien, maar nie die omvang daarvan in die gedig as geheel nie.

R G Bratcher \& W D Reyburn, A translator's handbook on the Book of Psalms, New York 1991, 484.

Anderson, $a w, 130$, meen die bestaan van die doeblet wys op die onafhanklike bestaan van die eerste Dawidiese versameling (Psalms 3-41) en van die Elohistiese bundel.

11 Dit beteken "daad" of "handeling", en word dikwels met God as subjek gebruik. Vergelyk L Koehler \& W Baumgartner, Lexicon in Veteris Testamenti libros, Leiden 1958, 708 ( $s$ v עִלְילָ).

$12 \quad$ Kraus, $a w, 219$.

13. Die vertaling "hom wat jou beleër het" veronderstel delesie van die voorsetsel לy.

14. Of: "In die raad teen die ellendige wil julle skaamteloos optree - waarlik, Jahwe is sy skuilplek". Vergelyk Koehler \& Baumgartner, $a w, 115$ ( $s v$ בוש). 
$17 \quad$ Kyk by 5.1 .

$18 \quad$ Weiser, $a w, 166$.

19 Vergelyk byvoorbeeld Gunkel, $a w, 232-235$, Deissler, $a w, 64-65, \mathrm{~J}$ Jeremias, $a w, 114-117$, Weiser, $a w, 166$.

Vergelyk ook die opmerkings van Zenger in dié verband $(a w, 99)$.

Die feit dat in dieselfde asem na Jahwe verwys word, maak dit onwaarskynlik dat Jahwe hier as die spreker bedoel word. Zenger, $a w, 100$, oordeel anders omdat "my volk" slegs op twee plekke in die Psalms anders as in 'n direkte JHWH-rede gebruik word. Die beswaar wat hier geopper word (die gelyktydige verwysing na Jahwe), word deur hulle afgemaak as sou dit "ongewoon", maar "nie onmoontlik nie", wees.

22 Jeremias, $a w, 116$, bring dit in verband met die toegang wat die profeet tot die raadsaal van God het, soos in Amos 3:7 en Jeremia 23:1 uiteengesit. Hierdie poging oortuig egter nie.

23 Die frase moet nie opgeneem word as 'n beskrywing van die universele boosheid van die mens nie, maar as ' $n$ hiperboliese beskrywing van die totale verdorwendheid van die goddelose.

$24 \quad$ Vergelyk byvoorbeeld Weiser, $a w, 164$; Anderson, $a w, 132$.

25 Anderson, $a w, 133$.

26 Die frase veronderstel God se teenwoordigheid in Sion. Vergelyk Bratcher \& Reyburn, $a w, 132$.

27 Anderson, $a w, 135$, neem die twee imperfekta as jussiewe op. Vergelyk ook Zenger, $a w, 101$, se opmerking. In kombinasie met die temporele frase in vers $7 \mathrm{~cd}$ maak dit egter minder sin as sou dit stellings wees.

Volgens Anderson, $a w, 131$, is daar redelike eenstemmigheid daaroor.

Aspekte wat hier aangeroer is, is die verandering van seker stellings tot ' $n$ afhanklike versoek, die identifikasie van die "my volk" (vers 4c) met "sy (Jahwe se) volk" (vers 7d), die gebruik van name vir God se volk en die oorgang van 'n wysheidstyl en -trant tot 'n klaagliedstyl.

Vergelyk Zenger, $a w, 100$, en Bennett, $a w, 19$. Anderson, $a w, 134$, oorweeg ook die moontlikheid. 